\title{
Symptom Burden of Patients with Haematological Malignancy
}

\author{
Siddika SS ${ }^{1 *}$, Rahman $\mathrm{MA}^{2}$, Islam $\mathrm{AKMM}^{3}$, Siddika ST ${ }^{4}, \mathrm{Akhtar}^{1}$, Siddika ${ }^{1}$ \\ ${ }^{1}$ Department of Community Medicine, Mugda Medical College, Dhaka, Bangladesh; ${ }^{2}$ Department of \\ Epidemiology, National Institute of Preventive and Social Medicine, Dhaka, Bangladesh; \\ ${ }^{3}$ Department of Haematology, National Institute of Cancer Research and Hospital, Dhaka, \\ Bangladesh; ${ }^{4}$ Department of Physiology, Mugda Medical College, Dhaka, Bangladesh
}

\begin{abstract}
Background: Haematological malignancy and its treatment produce multiple symptoms that significantly distress patients and impair function. Symptoms caused by treatment may delay treatment or lead to premature treatment termination and residual treatment-related symptoms often complicate post treatment rehabilitation. When treatment is no longer possible, symptom control becomes the focus of cancer care.
\end{abstract}

Objectives: The study was aimed to determine the symptom burden of the haematological malignancy patients.

Methods: A cross sectional study was conducted from July 2015 to June 2016 among the haematological malignancy patients. A total of 316 haematological malignancy adult (age $\geq 18$ years) patients were purposively selected from haematology department of two tertiary level of hospitals in Dhaka city. Face to face interviews were taken from the diagnosed haematological malignancy patients admitted in the hospital and attending outdoor using questionnaire based on symptom distress scale (SDS).

Results: Mean age was 39 years and most of the patients suffering from Acute Leukemia 162(51.3\%). Mean monthly family income was around 22235 taka and 120(37.9\%) patients were unemployed. Patients with haematological malignancy had a considerable physical and psychological symptom burden which ranged from $94.3 \%$ for fatigue to $8.5 \%$ for difficulty in concentration. Physical symptoms such as fatigue 127 (40.2\%), change in appetite $86(27.2 \%)$, pain1 $81(25.6 \%)$, insomnia44 (13.9\%) caused severedistress and psychological symptoms include change in appearance $37(11.7 \%)$ and outlook $33(10.4 \%)$ were sever distressing. Significant association $(p<0.001)$ was to be found between occupation and symptom distress where $82(68.4 \%)$ unemployed and $51(66.3 \%)$ housewife had moderate/sever symptom distress. Respondents who managed their treatment expenditure by loan and asset sell $11(84.6 \%)$ had significant $(p=0.004)$ moderate/sever distress. Patients having less than one month of diagnosis $47(72.3 \%)$ and admitted in inpatient $114(66.6 \%)$ had significant higher moderate/sever symptom distress $(p=0.03)$ and $(p<0.001)$ respectively.

Conclusion: Patients with haematological malignancy were likely to have multiple symptoms and comprehensive symptom assessment was suggested throughout. The introduction of supportiveor palliative care services during times of increased symptom burden may assist haematologists and other careers in the management of their patient's distress and quality of life.

Keywords: Haematological malignancy, Symptom burden, Symptom distress, Symptom distress stress

\section{Introduction}

The global burden from cancer is rising, especially lowincome countries like Bangladesh. WHO predicts that the number of blood-related cancer cases would increase about $48 \%$ in least developed countries by 2030 as compared to 2012 . Hematological malignancies (HM) comprise approximately $6.5 \%$ of all cancer incidences worldwide in 2012. ${ }^{1}$ The symptom burden in

*Correspondence: Dr. Syeda Subrina Siddaka, Department of Community Medicine, Mugda Medical College, Mugda, Dhaka, Bangladesh;

e-mail: drnipasubrina@gmail.com; ORCID:0000-0003-3322-031X patients with hematologic malignancies is attributable both to diseases as well as their treatments. Cleeland defines "Symptom Burden" as the combined impact of all symptoms related to the disease or the therapy on a person's ability to function as he or she did before the cancer journey begun. ${ }^{2}$ Dimensions of the symptom experience include symptom occurrence, frequency/duration, quality/intensity, interference with function, distress and bother. ${ }^{3}$ The disease is aggressive, requiring treatment that is often extensive and debilitating, and sometimes involving long periods 
of inpatient care (e.g. bone marrow transplant and chemotherapy). ${ }^{4,5}$ Treatment is equally variable and may include "watchful-waiting", chemotherapy, radiotherapy, immunotherapy and bone marrow transplant. ${ }^{4}$ The disease process in hematological malignancy and the intensive treatment regimens that are typically employed can result in substantial symptom burden. Physical and psychological distress were high and varied significantly according to disease stage and patient location. ${ }^{5}$

Different studies in these patients have revealed that in the last month of life, pain is reported by $27-76 \%$, shortness of breath by $44-50 \%$ and fatigue by $88 \%$. $^{6,7}$ Psychological symptom prevalence was also high, with at least $30 \%$ of patients feeling nervous, irritable, or sad, and $50 \%$ of patients feeling worried at least "occasionally" or "frequently" in greater than $75 \%$ of patients recruited. ${ }^{8,9}$ The cause of this findings may be the diagnosis of cancer itself, a fear or uncertainty of disease recurrence, and unemployment and financial strain associated with cancer diagnosis and treatment. ${ }^{10}$ The pattern of symptom prevalence fluctuates significantly depending on patient location, in hematological and advanced cancer patients. Inpatients reported significantly more lack of energy, drowsiness, dry mouth, feeling nervous, lack of appetite, sweats, mouth sores, feeling worried, cough, and weight loss than outpatients. ${ }^{11,12}$ These differences are likely because inpatients represent a more unwell population with increased uncertainties regarding treatment, procedures, and outcome. Inpatients often undergo more intensive treatment regimens that carry an increased likelihood of side effects, complications, and/or infection compared with outpatients. The patients with newly diagnosed, refractory or relapsed disease, a poorer performance status, and inpatients had higher global distress. ${ }^{11}$ The physical and psychological symptom burden have a high impact on diseases and treatment outcomes which contribute to increase distress and adversely affect quality of life ${ }^{11}$ and increase health care cost. ${ }^{11,13}$

Assessment of symptom prevalence, severity and distress might help the physicians and nurses to identify the high risk patients and facilitate earlier intervention and increased support, including palliative or supportive care, for the patients and carers. Supportive care or palliative care is a multidisciplinary model of care for the prevention and treatment of pain, symptoms, and stress among patients and families facing serious illness and should be applied concomitantly from the outset of a cancer diagnosis. ${ }^{7}$ Assessing symptom distress experienced by the supportive care patient presents an opportunity for the physician to develop a plan of care that is addresses the unique needs of the individual. An important task of the healthcare system is to assess, monitor, and prevent such symptoms and problems in order to help patients live as fully as possible with their disease. ${ }^{8}$ Therefore, the aim of this study was to determine the symptom burden of the haematological malignancy patients.

\section{Materials and Methods}

This cross-sectional study was carried out on 316 adult (age $\geq 18$ years) patients with diagnosis of haematological malignancy attending the outdoor and admitted in the indoor of the hematology department of Dhaka Medical College and Hospital and Bangabandhu Sheikh Mujib Medical University between July 2015 to June 2016. Data collection period was 3 months and each week there was six working days. It was about 72 working days. To interview each questionnaire, it was taken 30-45 minutes. For that, each day maximum 5 questionnaires were interviewed and the sample size was 72 X $5=360$, finally 316 samples were taken.

Seriously ill patients who were unable to take part in the interview were excluded from the study. Patients were purposively selected and face to face interviews were taken from the patients, using a pretested semi structured questionnaire. Ethical Clearance was obtained from the Institution Review Board (IRB) of National Institute of Preventive and Social Medicine, (NIPSOM) and permission was also obtained from hospital authority for conducting the study. Perspectives of the study were explained to the respondents and informed consent was taken from each respondent. The questionnaire included symptom distress scale (SDS). ${ }^{14}$ Socio demographics characteristics, diseases specific characteristics including types of hematological malignancy, patient location at the time of assessment, duration of diagnosis, treatment received over the past month and supportive care taking by the patients. Symptom Distress Scale (SDS) is a cancer-specific tool for assessing cancer-related symptoms and was developed by Professor Ruth McCorkle in 1977 based on 
interviews with patients between 1973 and1976. ${ }^{14}$ As a measure of overall symptom distress, the SDS has demonstrated evidence of reliability and validity in a wide variety of patients with cancer including those with hematological diseases. ${ }^{14,15}$ The SDS is a 13 item self-report questionnaire designed to identify physical and psychosocial symptoms of patients and the degree of distress associated with 11 symptoms. ${ }^{14}$ Subjects respond about how they have been feeling during the preceding week. For each symptom, participants rate "how they have been feeling lately" on a Likert scale with 1 indicating no problem with the symptom and 5 indicating the maximum amount of problems. Symptom prevalence was defined by a participants' rating of $\geq 2$ for any of the 11 symptoms on the SDS. It provided a measure of the severity of symptom distress in which symptom was indicated as mild (item score of 2), moderate (item score of 3) or severe (item score of 4 or 5). The total SDS score range from 13 to 65 with higher scores indicating a greater degree of distress. Total SDS score less than 25 indicates low symptom distress, 25 to 32 indicates moderate distress, and 33 and above indicates severe distress. ${ }^{14}$

Analyses of data were done by "Statistical Package for Social Science" (SPSS) version 21.Descriptive statistics were used to describe the socio-demographic and diseases characteristics of participants and characterize their symptom experience as derived from the SDS at each time point. SDS interpretive guidelines were used to create the following clinically meaningful symptom distress groups: low (SDS total score $<25$ ) and moderate/severe (SDS total score $\geq 25$ ). Relationships between symptom distress groups and selected socio-demographic and diseases characteristics variables were determine by using Chi Square test, as appropriate. $p<0.05$ was considered statistical significance. $^{14}$

\section{Results}

Among 316 respondents, maximum 97 (30.7\%) patients were completed secondary and higher secondary level of education and 120 (37.9\%) were unemployed. Mean monthly family income of the respondents were22235.7taka and majority of them were married 214 (67.7\%). Maximum patients $268(84.8 \%)$ managed their treatment expenditure from multiple sources and about 171(54.1\%) were in inpatient department. Most of the patients 186(58.9\%) were suffering from Hematological malignancy for one year and mean duration of confirm diagnosis was
9.9 months. Majority of the patients 248 (78.5\%) were received treatment over the past month. (table I)

Table I: Descriptive Statistics of Hematological Malignancy Patients $(\mathrm{n}=316)$

\begin{tabular}{lc}
\hline Patients information & $\mathbf{n}(\%)$ \\
\hline Marital status & \\
\hline Unmarried & $80(25.3)$ \\
Married & $214(67.7)$ \\
Others* & $22(7.00)$
\end{tabular}

\begin{tabular}{lc}
\hline Education & \\
\hline $\begin{array}{l}\text { Illiterate and primary level } \\
\text { incomplete }\end{array}$ & $75(23.7)$ \\
$\begin{array}{l}\text { Primary complete and Secondary } \\
\text { level incomplete }\end{array}$ & $90(28.5)$ \\
Secondary and Higher secondary & $97(30.7)$ \\
complete & \\
Graduate and above & $54(17.1)$ \\
\hline Occupation & \\
\hline Unemployed & $120(37.9)$ \\
Housewife & $77(24.5)$ \\
Service & $61(19.3)$ \\
Student & $37(11.7)$ \\
Farmer & $21(6.6)$ \\
\hline Monthly family income of the patients (in taka) \\
\hline$\leq 10000$ & $98(31)$ \\
$10001-25000$ & $134(42.7)$ \\
$26000-45000$ & $57(18.0)$ \\
$\geq 46000$ & $26(8.2)$ \\
Mean \pm SD & $22235( \pm 20294)$ \\
\hline
\end{tabular}

\begin{tabular}{lc}
\hline \multicolumn{2}{l}{ Source of treatment expenditure of the patients } \\
\hline Own money & $14(4.4)$ \\
Family member & $21(6.6)$ \\
Loan & $7(2.2)$ \\
Asset Sell or mortgage & $6(1.9)$ \\
Multiple sources & $268(84.8)$ \\
\hline
\end{tabular}

\begin{tabular}{lc}
\hline Hospital status of the patients & \\
\hline Inpatients & $171(54.1)$ \\
Outpatients & $145(45.9)$ \\
\hline Duration of diagnosis of the patients (in completed \\
month) & $65(20.6)$ \\
\hline$<1$ & $186(58.9)$ \\
$1-12$ & $34(10.8)$ \\
$13-24$ & $15(4.7)$ \\
$25-36$ & $16(5.1)$ \\
$>36$ & $9.9( \pm 19.5)$ \\
Mean \pm SD & \\
\hline Treatment received over the last month & \\
\hline Treatment received & $248(78.5 \%)$ \\
Treatment not received & $68(21.5 \%)$ \\
\hline
\end{tabular}

Others*- Separated / Divorced, Widow / Widower.

Note: Information about age, sex and different types of Hematological Malignancy Patients are given in table II. 
Mean age of the patients were 39.2 years and most of them suffering from Acute Leukemia162(51.3\%). Maximum Acute Leukemia patients $51(31.5 \%)$ were in 21-30 years, chronic Leukemia $15(30.6 \%)$ were in 31-40 years, Multiple myeloma $10(35.7 \%)$ were in 51-60 years and
Lymphoma and other types of Hematological malignancy were more common $3(27.3 \%)$ in old aged 51-60 years. All types of Hematological malignancy were predominantly observed in male. (table II)

Table II: Cross tabulation between age and sex distribution of different types of haematological malignancy patients $(n=316)$

\begin{tabular}{|c|c|c|c|c|c|c|}
\hline Characteristics & $\begin{array}{c}\text { Acute leukemia } \\
\text { n (\%) }\end{array}$ & $\begin{array}{c}\text { Chronic } \\
\text { leukemia } \\
\text { n (\%) }\end{array}$ & $\begin{array}{c}\text { Multiple } \\
\text { myeloma } \\
\text { n (\%) }\end{array}$ & $\begin{array}{c}\text { Lymphoma } \\
\text { n (\%) }\end{array}$ & $\begin{array}{c}\text { Others* } \\
\text { n }(\%)\end{array}$ & Total \\
\hline \multicolumn{7}{|c|}{ Age(in completed year) } \\
\hline$\leq 20$ years & $36(22.2)$ & $2(4.1)$ & $0(0.00)$ & $15(22.7)$ & $0(0.00)$ & $53(16.8)$ \\
\hline $21-30$ & $51(31.5)$ & $8(16.3)$ & $1(3.6)$ & $12(18.2)$ & $2(18.2)$ & $74(23.4)$ \\
\hline $31-40$ & $24(14.8)$ & $15(30.6)$ & $3(10.7)$ & $4(6.1)$ & $2(18.2)$ & $48(15.2)$ \\
\hline $41-50$ & $22(13.6)$ & $13(26.5)$ & $7(25.0)$ & $10(15.2)$ & $2(18.2)$ & $54(17.1)$ \\
\hline $51-60$ & $23(14.2)$ & $7(14.3)$ & $10(35.7)$ & $18(27.3)$ & $3(27.3)$ & $61(19.3)$ \\
\hline$>60$ & $6(3.7)$ & $4(8.3)$ & $7(25.0)$ & $7(10.6)$ & $2(18.2)$ & $26(8.2)$ \\
\hline Total & $162(51.3)$ & $49(15.5)$ & $28(8.9)$ & $66(20.9)$ & $11(3.5)$ & $316(100)$ \\
\hline Mean \pm SD & $39.20 \pm 16.18$ & & & & & \\
\hline \multicolumn{7}{|l|}{ Sex } \\
\hline Male & $99(61.1)$ & $34(69.4)$ & $17(60.7)$ & $47(71.2)$ & $9(81.8)$ & $206(65.2)$ \\
\hline Female & $63(38.9)$ & $15(30.6)$ & $11(39.3)$ & $19(28.8)$ & $2(18.2)$ & $110(34.8)$ \\
\hline Total & $162(100)$ & $49(100)$ & $28(100)$ & $66(100)$ & 11(100) & $316(100)$ \\
\hline
\end{tabular}

Others* --Myelodysplastic syndrome, Myelofibrosis, Polycythaemiavera

Level of symptom distress is shown in figure 1. Mean symptom distress score of the patients was 26.63 and most of them $138(43.7 \%)$ had low symptom distress.

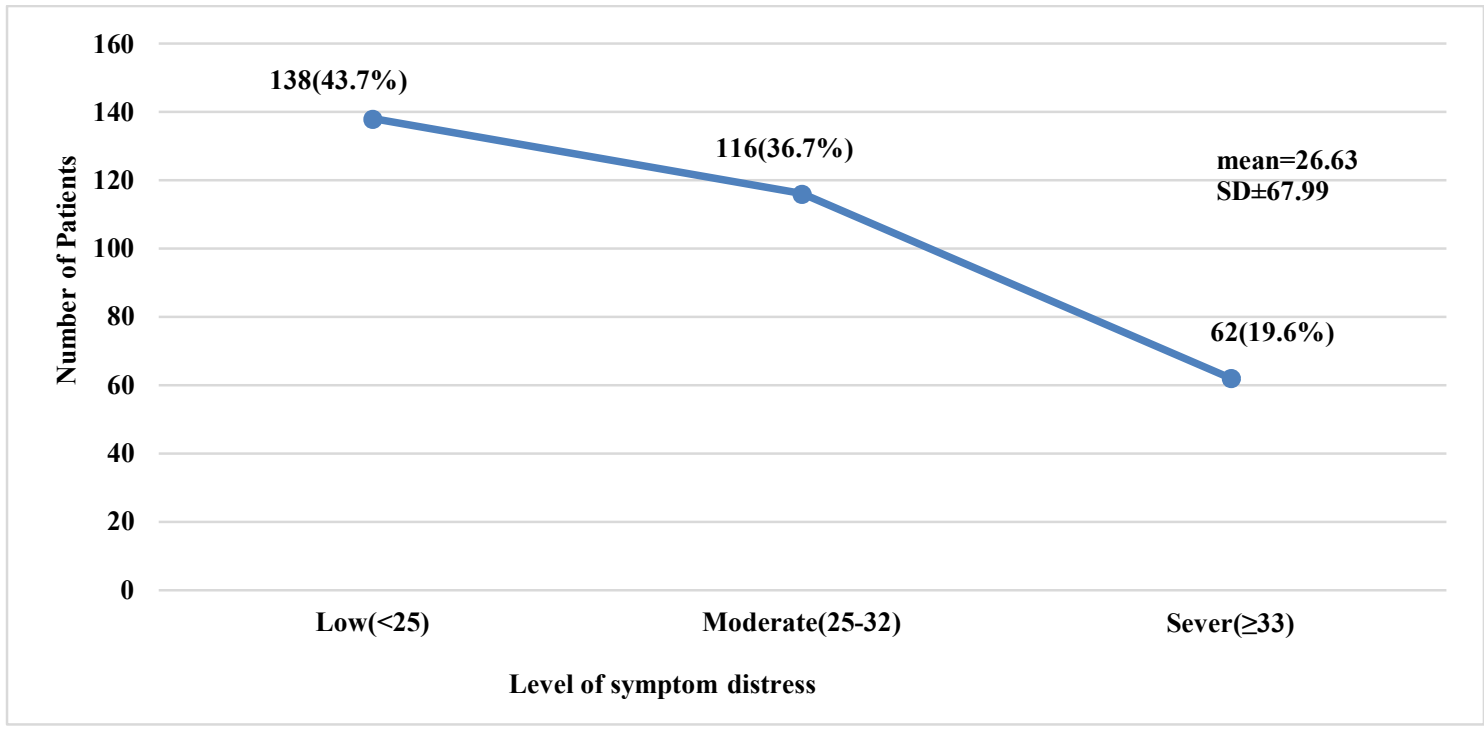

Figure 1: Level of symptom distress $(n=316)$

The most common physical symptoms reported by $90 \%$ to $60 \%$ of patients included fatigue 298 (94.3\%), appetite change 245 (77.5\%), pain1 239 (75.6\%), pain2 $222(70.3 \%)$, insomnia $218(69 \%)$, cough $156(49.4 \%)$ and psychological symptoms such as change of appearance $299(94.6 \%)$ and outlook 305 (96.5\%).Inpatients reported more physical symptoms they were fatigue $162(94.7 \%)$, appetite change $146(85.4 \%)$, pain1 $125(73.1 \%)$, pain2 117 (68.4\%), insomnia $135(78.9 \%)$, nausea 190 (52.6), 88 (51.5) and psychological symptoms such as change in outlook 169 (98.8\%), appearance $165(96.5 \%)$ and concentration 20 (11.7) than outpatients. Physical symptoms such as fatigue $127(40.2 \%)$, change in appetite 86 (27.2\%), pain1 $81(25.6 \%)$, insomnia $44(13.9 \%)$ 
caused severe distress and psychological (11.7\%) and outlook 33(10.4\%) were sever symptoms include change in appearance 37 distressing. (table III)

Table III: Proportion and degree of severity of symptoms in haematological malignancy patients

\begin{tabular}{|c|c|c|c|c|c|c|}
\hline Symptoms & $\begin{array}{c}\text { Overall } n=316 \\
n(\%)\end{array}$ & $\begin{array}{c}\text { Inpatient } \\
n=171 \\
n(\%) \\
\end{array}$ & $\begin{array}{c}\text { Outpatient } \\
n=145 \\
n(\%) \\
\end{array}$ & $\begin{array}{l}\text { Mild } \\
\text { n(\%) }\end{array}$ & $\begin{array}{c}\text { Moderate } \\
\mathbf{n}(\%)\end{array}$ & $\begin{array}{l}\text { Sever } \\
\text { n(\%) }\end{array}$ \\
\hline \multicolumn{7}{|l|}{ Physical symptoms } \\
\hline Nausea ${ }^{*}$ & $140(44.3)$ & $90(52.6)$ & $50(34.5)$ & $86(27.2)$ & $40(12.7)$ & $14(4.4)$ \\
\hline Nausea $2 * *$ & $135(42.7)$ & $88(51.5)$ & $47(32.4)$ & $74(23.4)$ & $34(10.8)$ & $27(8.5)$ \\
\hline Change in Appetite & $245(77.5)$ & $146(85.4)$ & $99(68.3)$ & $94(29.7)$ & $65(20.6)$ & $86(27.2)$ \\
\hline Insomnia & $218(69)$ & $135(78.9)$ & $83(57.2)$ & $87(27.5)$ & $87(27.5)$ & $44(13.9)$ \\
\hline Pain $1 * * *$ & $239(75.6)$ & $125(73.1)$ & $114(78.6)$ & $130(41.1)$ & $28(8.9)$ & $81(25.6)$ \\
\hline Pain $2 * * * *$ & $222(70.3)$ & $117(68.4)$ & $105(72.4)$ & $126(39.9)$ & $68(21.5)$ & $28(8.9)$ \\
\hline Fatigue & $298(94.3)$ & $162(94.7)$ & $136(93.8)$ & $51(16.1)$ & $120(38.0)$ & $127(40.2)$ \\
\hline Change in Bowel & $145(45.9)$ & $88(51.5)$ & $57(39.3)$ & $109(34.5)$ & $31(9.8)$ & $5(1.6)$ \\
\hline Breathing difficulty & $117(37)$ & $72(42.1$ & $45(31.0)$ & $96(30.4)$ & $18(5.7)$ & $3(0.9)$ \\
\hline Cough & $156(49.4)$ & $83(48.5)$ & $73(50.3)$ & $119(37.7)$ & $20(6.3)$ & $17(5.4)$ \\
\hline \multicolumn{7}{|l|}{ Psychological symptoms } \\
\hline Change in concentration & $27(8.5)$ & $20(11.7)$ & $7(4.8)$ & $22(7.0)$ & $5(1.6)$ & $0(0.0)$ \\
\hline Change in appearance & $299(94.6)$ & $165(96.5)$ & $134(92.4)$ & $191(60.4)$ & $71(22.5)$ & $37(11.7)$ \\
\hline Change in outlook & $305(96.5)$ & $169(98.8)$ & $136(93.8)$ & $151(47.8)$ & $121(38.3)$ & $33(10.4)$ \\
\hline
\end{tabular}

Nausea $1 *$--Time of occurrence of Nausea, Nausea $2 *$--Severity of Nausea

Pain $1 * * *$--Time of occurrence of Pain, Pain $2 * * * *$--Severity of Pain

Significant association $(p<0.001)$ was found between occupation and symptom distress and Majority of the Unemployed $82(68.4 \%)$ and Housewife $51 \quad(66.3 \%)$ had moderate/sever symptom distress. Moderate $\&$ Sever distress were more common in patients who managed their treatment expenditure by loan and asset selling 11 $(84.6 \%)$ and these differences in proportion was significant $(\mathrm{p}=0.004)$. (table IV)

Table IV: Association of symptom distress and occupation and source of treatment expenditure

\begin{tabular}{|c|c|c|c|c|}
\hline \multirow[t]{2}{*}{ Occupation } & \multicolumn{2}{|c|}{ Symptom Distress } & \multirow[t]{2}{*}{$x^{2}$} & \multirow[t]{2}{*}{$p$} \\
\hline & $\begin{array}{c}\text { Low } \\
\text { n (\%) }\end{array}$ & $\begin{array}{c}\text { Moderate/Severe } \\
\text { n (\%) }\end{array}$ & & \\
\hline $\begin{array}{l}\text { Unemploy } \\
\text { ed }\end{array}$ & $38(31.7)$ & $82(68.4)$ & $\begin{array}{c}35.8 \\
1\end{array}$ & $\begin{array}{c}<0.00 \\
1\end{array}$ \\
\hline Housewife & $26(33.8)$ & $51(66.3)$ & & \\
\hline Services & $38(62.3)$ & $23(37.8)$ & & \\
\hline Student & $23(62.2)$ & $14(37.8)$ & & \\
\hline Farmer & $13(61.9)$ & $8(38.1)$ & & \\
\hline \multicolumn{5}{|c|}{ Source of treatment expenditure } \\
\hline $\begin{array}{l}\text { Own \& } \\
\text { family } \\
\text { member }\end{array}$ & $15(42.9)$ & $20(57.1 \%)$ & $\begin{array}{c}15.4 \\
4\end{array}$ & 0.004 \\
\hline $\begin{array}{l}\text { Loan and } \\
\text { Asset } \\
\text { Selling }\end{array}$ & $2(15.4)$ & $11(84.6 \%)$ & & \\
\hline $\begin{array}{l}\text { Multiple } \\
\text { sources }\end{array}$ & $121(45.1)$ & $147(54.8)$ & & \\
\hline
\end{tabular}

Majority of Multiple Myeloma patients have moderate/severe distress 22(78.6\%).

Table V: Association of symptom distress and diseases and treatment characteristics

\begin{tabular}{|c|c|c|c|c|}
\hline \multirow[t]{2}{*}{ Characteristics } & \multicolumn{2}{|c|}{ Symptom Distress } & \multirow[t]{2}{*}{$\mathbf{x}^{2}$} & \multirow[t]{2}{*}{$p$} \\
\hline & $\begin{array}{c}\text { low } \\
\text { n (\%) }\end{array}$ & $\begin{array}{c}\text { moderate } \\
\text { / Severe } \\
\text { n }(\%)\end{array}$ & & \\
\hline \multicolumn{5}{|c|}{ Types of haematological malignancy } \\
\hline $\begin{array}{l}\text { Acute } \\
\text { Leukemia }\end{array}$ & $76(46.9)$ & $86(53.1)$ & 7.19 & 0.52 \\
\hline $\begin{array}{l}\text { Chronic } \\
\text { Leukemia }\end{array}$ & $22(44.9)$ & $27(55.1)$ & & \\
\hline $\begin{array}{l}\text { Multiple } \\
\text { Myeloma }\end{array}$ & $6(21.4)$ & $22(78.6)$ & & \\
\hline Lymphoma & $28(42.4)$ & $38(57.6)$ & & \\
\hline Others* & $6(54.5)$ & $5(45.5)$ & & \\
\hline \multicolumn{5}{|c|}{ Duration of diagnosis (in month) } \\
\hline$<1$ & $18(27.7)$ & $47(72.3)$ & 17.0 & 0.03 \\
\hline $1-12$ & $80(43.0)$ & $106(57.0)$ & 8 & \\
\hline $13-24$ & $22(64.7)$ & $12(35.3)$ & & \\
\hline $25-36$ & $10(66.7)$ & $5(33.3)$ & & \\
\hline$>36$ & $8(50.0)$ & $8(50.0)$ & & \\
\hline \multicolumn{5}{|c|}{ Treatment received over the past month } \\
\hline $\begin{array}{l}\text { Treatment } \\
\text { received }\end{array}$ & $111(44.8)$ & $137(55.2)$ & 1.64 & 0.44 \\
\hline $\begin{array}{l}\text { Treatment not } \\
\text { received }\end{array}$ & $27(39.7)$ & $41(60.3)$ & & \\
\hline \multicolumn{5}{|l|}{ Hospital status } \\
\hline Inpatient & $57(33.3)$ & $114(66.6)$ & 17.2 & $<.00$ \\
\hline Outpatient & $81(55.9)$ & $64(44.1)$ & 7 & 1 \\
\hline
\end{tabular}

Others*-Myelodysplastic syndrome, Myelofibrosis, Polycythaemia vera 
Higher proportion of patients having less than one month of confirm diagnosis had moderate /severe symptom distress 47(72.3\%).These differences in proportion was significant $(p=0.03)$. Significantly higher proportion of patients who received treatment 137(55.2\%) experienced moderate and severe symptom distress. Moderate /severe symptom distress were more common in the inpatient $114(66.6 \%)$ and there different was significant $(p<0.001)$ (table V)

\section{Discussion}

Comprehensive symptom assessment is essential in the care of all cancer patients, as symptom burden has an impact upon patient distress, quality of life, and survival. ${ }^{16,17}$ In this study mean age of the Haematological malignancy (HM) patients were 39.2 years and male $206(65.2 \%)$ were twice than the female $110(34.8 \%)$. Hossain et al found that median age at diagnosis was 42 years and men were more involved than women, with male to female ratio was of $2.2: 1 .^{18}$ In a recent study on symptom burden of haematological patients by Manitta et al (2011), fatigue was the most reported symptom $124(\% 69)$, followed by insomnia 74 (\%41), pain $71(\% 39)$, cough59 (\%33) and lack of appetite $48(\% 27) .{ }^{11}$ This study reported higher rates of fatigue possibly because higher proportion of patients being inpatients171(54.1\%) or on treatment $248(78.5 \%)$. In this study change of appearance $(94.6 \%)$ and outlook $(96.5 \%)$ were the more common psychological symptoms. These were also supported by the several studies, which indicates that haematological malignancy patients are at risk of psychological morbidity. ${ }^{10,11}$ Probable reason for this situation include the diagnosis itself, a fear or uncertainty of disease recurrence, and unemployment and financial strain associated with cancer diagnosis and treatment in cancer survivors.$^{10,19}$ In a study of 180 patients with haematological malignancy conducted by Manitta et alreported significantly more lack of energy, drowsiness, dry mouth, feeling nervous, lack of appetite, sweats, mouth sores, feeling worried, cough in inpatients than outpatientswhich are most similar with our findings. ${ }^{11}$

Severe distressing symptoms in our study including fatigue $127(40.2 \%)$, change in appetite $86(27.2 \%)$, pain $181(25.6 \%)$, insomnia $44(13.9 \%)$ and change in appearance $37(11.7 \%)$ and worried or frightened about future $33(10.4 \%)$. These findings is not similar with Manitta et al where severe symptoms had higher proportion than our study except fatigue which was most distressing. ${ }^{11}$ This may be due to patients with severe distressing symptoms were excluded from our study due to their unstable condition. Significant association $(p<0.001)$ was found between occupation and symptom distress and majority of the unemployed $82(68.4 \%)$ and housewife $51(66.3 \%)$ had moderate/severe symptom distress. Moderate \& Sever distress were more common in patients who managed their treatment expenditure by loan and asset selling 11 $(84.6 \%)$ and these differences in proportion was significant $(p=0.004)$. Majority of Multiple Myeloma patient had moderate/sever symptom distress $22(78.6 \%)$. Johnsen et al found in his study that patients with multiple myeloma had most symptoms and problems and their mean number of symptoms was 5.6 ; severe symptoms score was 2.3 which was more than other haematological malignancy. ${ }^{20}$ Patients on treatment, inpatients and those with newly diagnosed had found high physical and psychological distress in the study conducted by Manitta et al which was similar with our study. ${ }^{11}$ Possible explanation that inpatients represent a more unwell population with increased uncertainties regarding treatment, procedures, and outcome and often undergo more intensive treatment regimens that has increased side effects, complications, and/or infection compared with outpatients. A small proportion of patients were too ill to participate in the study, thus the symptom burden of these more vulnerable population may not be fully understood.

\section{Conclusion}

The physical and psychological symptom burdens experienced by haemato-oncological patients were significantly moderate and severe distressing. Such a symptom burden was likely tohave a high impact on disease and treatment outcomes, and adversely affect quality of life in these patients. For better control of the symptoms and reduce symptom distress we should facilitated earlier intervention and increased support, including palliative care, for patients and careers.

\section{Acknowledgement}

Authors acknowledge the valuable suggestions of Professor Md. Ziaul Islam, Department of Community Medicine, NIPSOM and Dr. Syed Muhammad Baqui Billah, Assistant Professor of Epidemiology, Sher-e Bangla Medical College, Barisal, to conduct this study. 
Symptom burden in haematological malignancy

Conflict of interest: The authors have no conflict of interest.

Funding: None

Ethical approval: IRB of NIPSOM, Dhaka

Submitted: $13^{\text {th }}$ November, 2019

Final revision received: $16^{\text {th }}$ March, 2020

Accepted: $19^{\text {th }}$ March, 2020

Published: $1^{\text {st }}$ December, 2020

\section{References}

1. Ferlay J, Soerjomataram I, Ervik M, Dikshit R, Eser S, Mathers C, Rebelo M, Parkin DM, Forman D, Bray F.Cancer incidence, mortality and prevalence worldwide in 2012: Globocan 2012. France: International agency for research on Cancer.

2. Cleeland C. Surviving survival: The symptom burden of cancer and cancer treatment. Blood.2006.

3. GoodellTT, Nail LM.Operationalizing symptom distress in adults with cancer: a literature synthesis. OncolNurs Forum .2011; 32:E42-E47. DOI: 10.1188/05.onf.e42-e47

4. Guidance on cancer services improving outcomes in haematological cancers: the manual. London: National Health Service.National Institute for Clinical Excellence NICE.2003

5. Sherman RS, Cooke E,Grant M. Dialogue among survivors of hematopoietic cell transplantation: support-group themes. Journal of Psychosocial Oncology. 2005;23:1-24.

DOI: $10.1300 / J 077 \mathrm{v} 23 \mathrm{n} 0101$

6. Bauduer F, CapdupuyC ,Renoux M, Characteristics of deaths in a department of onco -hematology within a general hospital. Support Care Cancer.2000; 8:302-6.

7. Maddocks I, Bentley Land, Sheedy J. Quality of life issues in patients dying from haematological diseases. Ann Acad Med Singapore. 1994; 23:244-8.

PMID: 8080225

8. Fey MF. Salient features of hematological diseases. Ann Oncol. 2007; 18:i54-i64.

DOI: $10.1093 /$ annonc/mdl452

9. Laird BJA, Scott AC, Colvin LA, McKeon AL, Murray GD, FearonKCH, Fallon MT. Pain, depression and fatigue as a symptom cluster in
Siddika SS at el

advanced cancer. J Pain \& Symptom Management.2011;12:1-11.

DOI: 10.1016/j.jpainsymman.2010.10.261

10. Black EK, White CA.Fear of recurrence, sense of coherence and posttraumatic stress disorder in hematological cancer survivors.2005; 14: 510-15. DOI: $10.1002 /$ pon. 894

11. Manitta V, Zordan R, Cole-Sinclair M, Nandurkar H, Philip J. The symptom burden of patients with hematological malignancy: a crosssectional observational study. J Pain Symptom Manage. 2011; 42:432-42.

DOI: 10.1016/j.jpainsymman.2010.12.008

12. Johnsen AT, Tholstrup D, Petersen MA, Pedersen L, Groenvold M. Health related qualityof life in a nationally representative sample of hematological patients. European Journal of Haematology. 2009 ;83:139-48.

DOI: 10.1111/j.1600-0609.2009.01250.x

13. Zabora J, BrintzenhofeSzoc K, Curbow B, Hooker C,Piantadosi S. The prevalence of psychological distress by cancer site.2001; 10:19-28.

PMID: 11180574

14. McCorkle R, Cooley ME, Shea JA. The user's manual for the Symptom Distress Scale.1994.

15. Diez-Campelo M, Perez-Simon JA, GonzalezPorras JR, Garcia-Cecilia JM, Salinero M, Caballero MD. Quality of life assessment in patients undergoing reduced intensity conditioning allogeneic as compared to autologous transplantation: results of a prospective study. Bone Marrow Transplant. 2004; 34:729-738.

DOI: $10.1038 /$ sj.bmt. 1704646

16. Kirkova J, Davis MP, Walsh D, et al. Cancer symptom assessment instruments: a systematic review. J ClinOncol.2006; 24:1459e1473.

DOI: $10.1200 / J C O .2005 .02 .8332$

17. Chang VT, Hwang SS, Feuerman M, Kasimis BS. Symptom and quality of life survey of medical oncology patients at a veterans affairs medical center: a role for symptom assessment. Cancer. 2000;88: 1175e1183. DOI: 10.1002/(sici)1097-0142(20000301)88:5<1175 ::aid-cncr30>3.0.co;2-n 
18. Hossain MS, Iqbal MS, Khan MA, Rabbani MG, Khatun H, Munira S, Miah MMZ, Kabir AL, Islam N, Dipta TF, Rahman F, Mottalib A, Afrose S, Ara T, Biswas AR, Rahman M, Abedin AKMM, Rahman M, Yunus ABM, Niessen LW, Sultana TA. Diagnosed hematological malignancies in Bangladesh,a retrospective analysis of over 5000 cases from 10 specialized hospitals.2014; 14:438.

19. Lobb EA, Joske D, ButowP, Kristjanson LJ, Cannell P, Cull G , AugustsonB.
Whenthesafety net of treatment has been removed: patients'unmetneeds at the completion of treatment forhaematological malignancies. Patient EducCouns. 2009; 77:103-8.

DOI: 10.1016/j.pec.2009.02.005

20. Johnsen AT, Tholstrup D, Petersen MA, Pedersen L, Groenvold M. Health related qualityof life in a nationally representative sample of hematological patients. European Journal of Haematology. 2009 ;83:139-48.

DOI: $10.1111 /$ j.1600-0609.2009.01250.x 